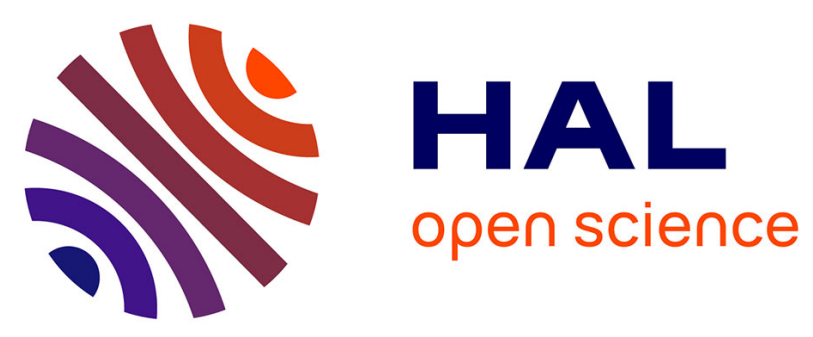

\title{
Evaluation and Mapping of Rice Flood Damage Using Domestic Remotely Sensed Data in China
}

Huifang Wang, Xiaoyi Fang, Wei Guo, Yonghong Liu, Qingzu Luan, Shuo Zhang, Yanhu Gao

\section{To cite this version:}

Huifang Wang, Xiaoyi Fang, Wei Guo, Yonghong Liu, Qingzu Luan, et al.. Evaluation and Mapping of Rice Flood Damage Using Domestic Remotely Sensed Data in China. 11th International Conference on Computer and Computing Technologies in Agriculture (CCTA), Aug 2017, Jilin, China. pp.143-151, 10.1007/978-3-030-06137-1_15. hal-02124222

\section{HAL Id: hal-02124222 \\ https://hal.inria.fr/hal-02124222}

Submitted on 9 May 2019

HAL is a multi-disciplinary open access archive for the deposit and dissemination of scientific research documents, whether they are published or not. The documents may come from teaching and research institutions in France or abroad, or from public or private research centers.
L'archive ouverte pluridisciplinaire HAL, est destinée au dépôt et à la diffusion de documents scientifiques de niveau recherche, publiés ou non, émanant des établissements d'enseignement et de recherche français ou étrangers, des laboratoires publics ou privés. 


\title{
Evaluation and mapping of rice flood damage using domestic remotely sensed
}

\author{
data in China \\ Huifang Wang ${ }^{1}$, Xiaoyi Fang ${ }^{1(凶)}$, Wei Guo ${ }^{2}$, Yonghong Liu ${ }^{1}$, Qingzu Luan ${ }^{1}$, Shuo Zhang ${ }^{1}$, Yanhu Gao ${ }^{1}$, \\ 1. Beijing Municipal Climate Center, Beijing, 100089, China. \\ 2. Henan Agricultural university, Zhengzhou, 450002, China
}

\begin{abstract}
It has great significance to study quick monitoring of rice flood disaster and applying timely remedial measures in the disaster area. The purpose of this research paper was to evaluate the rice flood damage, which happened on July to August 2009 in Shouxian, Huoqiu, Bengbu and Huainan are mainly rice producing areas in Anhui Province in China, using two images from domestic remotely sensing data from China that named Huan Jing satellite (HJ-CCD images). One was pre-flood disaster and the other was post-flood disaster. According to the change characteristics of NDVI (Normalized Difference Vegetation Index) of forty field-sampling points of post-flood in study area, the flood damage degrees (light, moderate and serious) were been classified also. The verification of the classification accuracy calculated by confusion matrix that based on 40 field-sampling verification points. Accuracy results showed that Kappa coefficient ( $\kappa$ ) was 0.6907 and the overall accuracy was 80.0\%. At the same time, extract nine vegetation indices calculated from HJ-CCDs data were to build the model to inverted LAI of rice, and analyze the growth of rice after flood disaster stress. Hence, this study descripted that multi-temporal and multispectral imagery domestic remotely sensing data from China (HJ-1 CCD images) are sufficient to assess rice flood disaster areas, specify relative damage degrees and growth analysis after flood stress.
\end{abstract}

Keywords: Remote sensing, NDVI Change characters detection, Rice flood disaster degree, HJ-CCD

\section{Introduction}

Flood disaster is an important type of disaster related to changes in global. It has serious impact on agricultural production and development of the national economy [1, 2]. Monitoring rice flood disaster and assessing the damage scientifically and rapidly has an important significance for the development of insurance claims and compensation after disaster [3]. Damage assessment of existing research mainly concentrated on the aspects of population, infrastructure and social economy. Rice flood damage assessment is more complex, not only have to extract submerged area and duration of crop, but also must consider the crop variety, fertilizer, growth stage, soil texture and other factors, so the monitoring and evaluation of flood disaster for rice is rarely involved, which lead to the lack of basic, theoretical and practical research achievements. Current researches of flood disaster monitoring and evaluation have some limitations, especially monitoring crop disaster at a wide range spatial scale. Past years, the traditional crop flood damage monitoring and loss estimation method mainly depends on labor-intensive field investigations by randomly selecting some field-sampling points.

With the rapid development of the earth observation technology, remote sensing (RS) technology have been playing an extremely important role in the flood monitoring and application of flood disaster. The advantage of RS technology is obtaining temporal and spatial information of feature information timely, accurately and rapidly. The precision of rice flood disaster monitoring, disaster assessment has been greater improved than before. Among them, the NOAA/AVHRR, MODIS, 
Landsat5\7 TM, Landsat8/OLI, HJ/CCD, GF1/WFV and so on, have been research focus on extracting the spatial distribution of rice flooded area precisely. HJ-CCD is China's independent research and development of small satellite constellation, its purpose is to monitor the environment and disaster losses.

Current researches of flood disaster monitoring and evaluation have some limitations, especially at a wide range spatial scale [4-7]. So this paper selected two domestic HJ-CCDs data, which covering key growth periods of rice, were used for analyzing and comparing the rice growing characterization parameters-NDVI, change information after flood disaster. Then the growth evaluation system of rice was built after flood disaster, spatial and temporal change information of rice growth was analyzed quantitatively, rice disaster situation was predicted, in order to improve the HJdata potential applications in crop disaster monitoring. This study can provide decision support for rice production and management for the government departments' guide.

\section{Materials and Method}

According to the research area phenological characteristics and remote sensing image transit time, two HJ - CCD images were obtained during July to August in 2009 and were covered major growth period of rice, images acquisition and imaging parameters as shown in Table 1.

Field sampling was carried out after continuous rainfall in study area in July 2009. Forty of them were used for flood damage level classification verification. The area of each sample plot was at least no less than 10 ha and located more than 100 meters away from the road. The sample plots were positioned by GPS. Five-point sampling method was used. In addition, other data also includes vector border of counties in Anhui Province and the multi-physiological parameter.

Table1. Acquired images from the HuanJing-A/B CCDs (HJ-CCDs) and technical specifications

\begin{tabular}{|c|c|c|c|c|c|}
\hline Sensors and orbiter & $\begin{array}{c}\text { The image } \\
\text { acquisition } \\
\text { date }\end{array}$ & $\begin{array}{l}\text { Spectral band range } \\
\qquad /(\mu \mathrm{m})\end{array}$ & $\begin{array}{c}\text { Spatial } \\
\text { resolution(m) }\end{array}$ & $\begin{array}{c}\text { Revisiting } \\
\text { cycle } \\
\text { (days) } \\
\end{array}$ & Swath width \\
\hline $\begin{array}{c}\text { HuanJing-1A- } \\
\text { CCD-1 } \\
\text { (456/76) } \\
\text { HuanJing-1A- } \\
\text { CCD-2 (454/76) }\end{array}$ & 2009-08-19 & $\begin{array}{l}\text { Band 1: } 0.43-0.52 \\
\text { Band 2: } 0.52-0.60 \\
\text { Band 3: 0.63-0.69 } \\
\text { Band 4: 0.76-0.90 }\end{array}$ & 30 & 4 & $\begin{array}{c}\text { 360/700 } \\
\text { km(single/dual } \\
\text { CCD/CCDs) }\end{array}$ \\
\hline
\end{tabular}

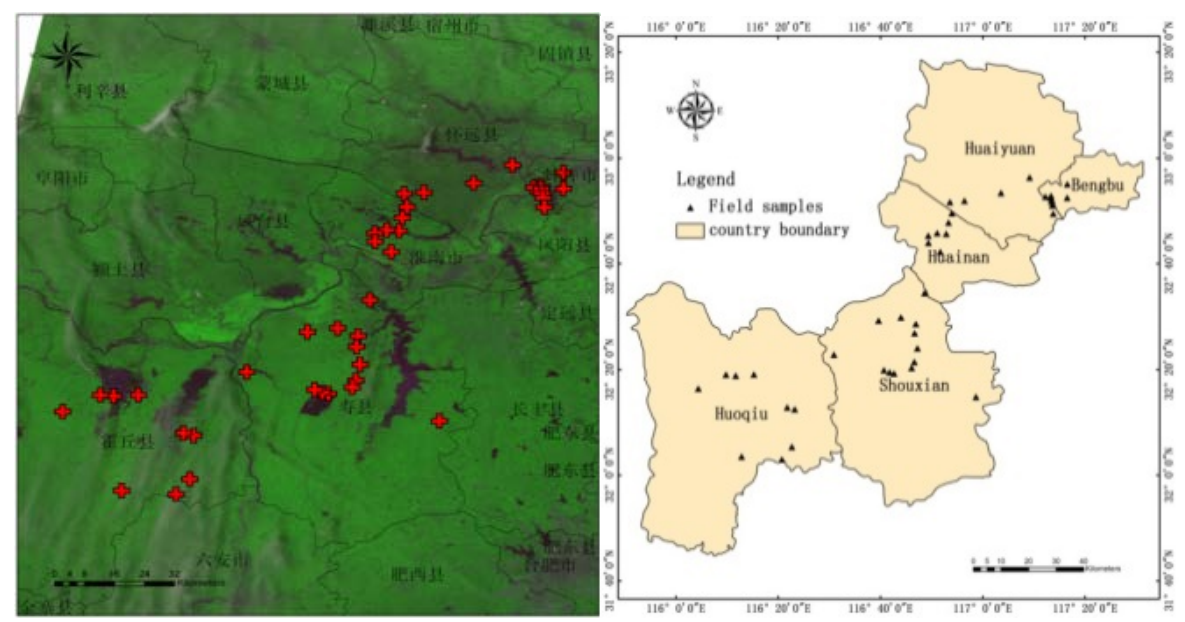

Figure.1 Location of field samples 
In this paper, from HuanJing-1(A/B) CCDs (HJ-CCDs) satellite images were been used to estimate the flood-damaged rice area. The analysis result performed in terms of rice flood damage levels.

In order to detect vegetation changes quickly and accurately in rice planting area, a $\Delta$ NDVI image was generated by subtracting the values between the before flood disaster image and the afterflood disaster image. Formulas of calculated NDVI and $\triangle$ NDVI were as follow:

$$
N D V I=\frac{\left(\text { Band }_{\text {NearIR }}-\text { Band }_{R E D}\right)}{\left(\text { Band }_{\text {NearIR }}+\text { Band }_{R E D}\right)}
$$

Where, Band $\mathrm{BearIR}_{\text {( }}(0.76 \mu \mathrm{m}-0.90 \mu \mathrm{m})$ and $\operatorname{Band}_{R E D}(0.63 \mu \mathrm{m}-0.69 \mu \mathrm{m})$ represent the two spectral bands (Near infrared band \& red band) of HJ-CCDs images:

$$
\Delta N D V I=N D V I_{p o t t}-N D V I_{p r e}
$$

Where, $N D V I_{\text {pre }}$ and $N D V I_{\text {post }}$ are the $N D V I$ images pre and post-flood damage, respectively.

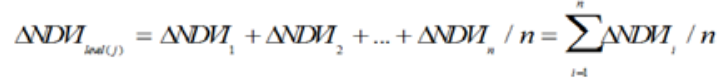

Where $\triangle N D V I_{\text {level }(j)}$ is the mean for each level $_{(j)}$ and $i=(1,2, \ldots, n)$ represents the sample position, of which $n$ is the total number of sample positions for three different damage levels.

$$
\begin{aligned}
& L_{\text {seriss }}=\overline{\Delta N D V I_{s \text { min }}} \leq \Delta N D V I \leq \overline{\Delta N D V I} \\
& L_{\text {mad eave }}=\overline{\Delta N D V I_{m \text { min }}} \leq \Delta N D V I \leq \overline{\Delta N D V I_{m \text { mat }}}
\end{aligned}
$$

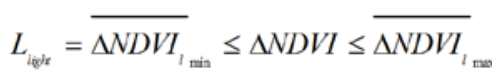

where $L_{\text {serious }}, L_{\text {moderate }}$ and $L_{\text {light }}$ represent the three damage degrees (serious, moderate and light, respectively.) and $\Delta N D V I_{x_{\max }}$ and $\Delta N D V_{x \min }$ represent the minimum and maximum values of the three damage levels, which are derived by calculating the mean of less than or greater than median for sampling points with three damage levels.

At the same time, we use the wide-band image of HJ-CCDs data which covering the visible light region to invert the physiological and biochemical parameters of vegetation growth. The inversion physiological and biochemical parameters often use wide-band reflectance to perform the different combinations of the vegetation index. The article refers to the existing studies on rice LAI inversion. The study selected wide-spectrum multispectral data been selected to combine different vegetation indices. These vegetation indices included not only the commonly used red and near-infrared bands, but also the reflectivity of the blue and green bands to account for the growing situation of rice under flooding stress. Conduct monitoring. The detailed calculation formula been showed in table 2: 
Table 2. Vegetation index of LAI inversion formula

\begin{tabular}{|c|c|c|}
\hline $\begin{array}{l}\text { Vegetation } \\
\text { Index }\end{array}$ & Formula & references \\
\hline NDVI & $N D V I=\left(R_{N I R}-R_{R E D}\right) /\left(R_{N I R}+R_{R E D}\right)$ & $\begin{array}{l}\text { Rouse et al. } \\
\text { (1974) }\end{array}$ \\
\hline EVI & $E V I=2.5 \frac{R_{N I R}-R_{R E D}}{1+\rho_{N I R}+6 R_{R E D}-7.5 R_{B L U E}}$ & $\begin{array}{l}\text { Huete et al. } \\
\text { (1997) }\end{array}$ \\
\hline $\begin{array}{l}\text { Green } \\
\text { NDVI }\end{array}$ & $G N D V I=\left(R_{N I R}-R_{G R E E N}\right) /\left(R_{N I R}+R_{G R E E N}\right)$ & $\begin{array}{l}\text { Gitelson et al. } \\
\text { (2001) }\end{array}$ \\
\hline $\begin{array}{l}\text { Blue } \\
\text { NDVI }\end{array}$ & $B N D V I=\left(R_{N I R}-R_{B L U E}\right) /\left(R_{N I R}+R_{B L U E}\right)$ & $\begin{array}{l}\text { Wang F M. et } \\
\text { al. (2007) }\end{array}$ \\
\hline $\begin{array}{l}\text { Green-Red } \\
\text { NDVI }\end{array}$ & $G R N D V I=\left[R_{N I R}-\left(R_{G R E E N}+R_{R E D}\right)\right] /\left[R_{N I R}+\left(R_{G R E E N}+R_{R E D}\right)\right]$ & $\begin{array}{l}\text { Wang F M et } \\
\text { al. (2007) }\end{array}$ \\
\hline $\begin{array}{l}\text { Green- } \\
\text { Blue } \\
\text { NDVI }\end{array}$ & $G B N D V I=\left[R_{N I R}-\left(R_{G R E E N}+R_{B L U E}\right)\right] /\left[R_{N I R}+\left(R_{G R E E N}+R_{B L U E}\right)\right]$ & $\begin{array}{l}\text { Wang F M et } \\
\text { al. (2007) }\end{array}$ \\
\hline $\begin{array}{l}\text { Red-Blue } \\
\text { NDVI }\end{array}$ & $R B N D V I=\left[R_{N I R}-\left(R_{R E D}+R_{B L U E}\right)\right] /\left[R_{N I R}+\left(R_{R E D}+R_{B L U E}\right)\right]$ & $\begin{array}{l}\text { Wang F M et } \\
\text { al. (2007) }\end{array}$ \\
\hline Pan NDVI & $P N D V I=\left[R_{N I R}-\left(R_{G R E E N}+R_{R E D}+R_{B L U E}\right)\right] /\left[R_{N I R}+\left(R_{G R E E N}+R_{R E D}+R_{B L U E}\right)\right]$ & $\begin{array}{l}\text { Wang F M et } \\
\text { al. (2007) }\end{array}$ \\
\hline ANDVI & $A N D V I=\frac{R_{N I R}-R_{R E D}+(1+0.5)\left(R_{G R E E N}-R_{B L U E}\right)}{R_{N I R}+R_{R E D}+(1+0.5)\left(R_{G R E E N}+R_{B L U E}\right)}$ & $\begin{array}{l}\text { Liu Z Y. et al. } \\
\qquad(2008)\end{array}$ \\
\hline
\end{tabular}

\section{Result}

\subsection{Distribution and degrees of Rice flood damage}

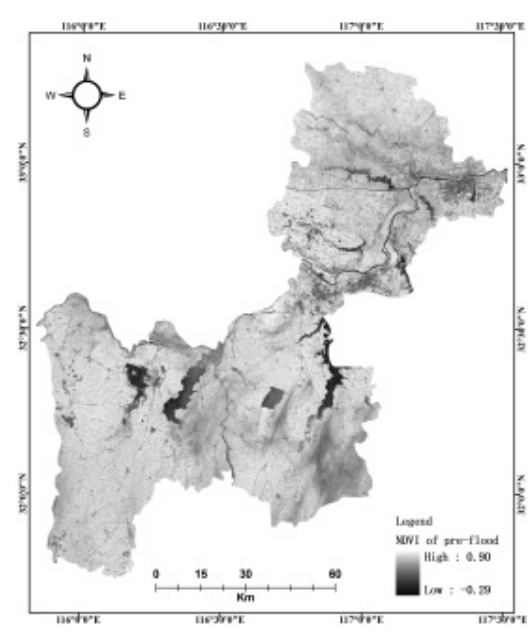

(a)

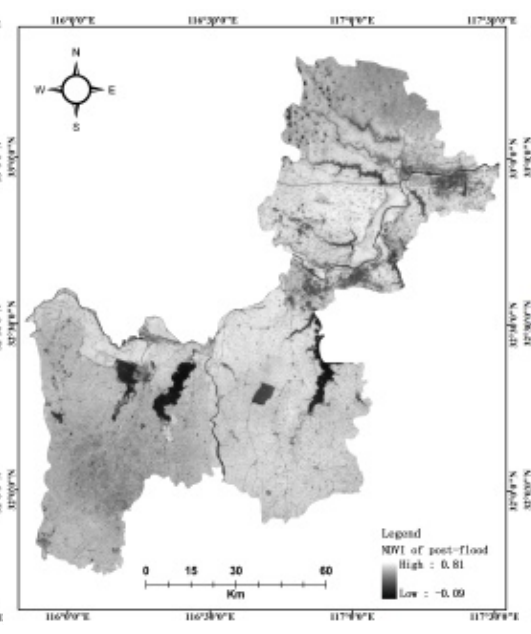

(b)

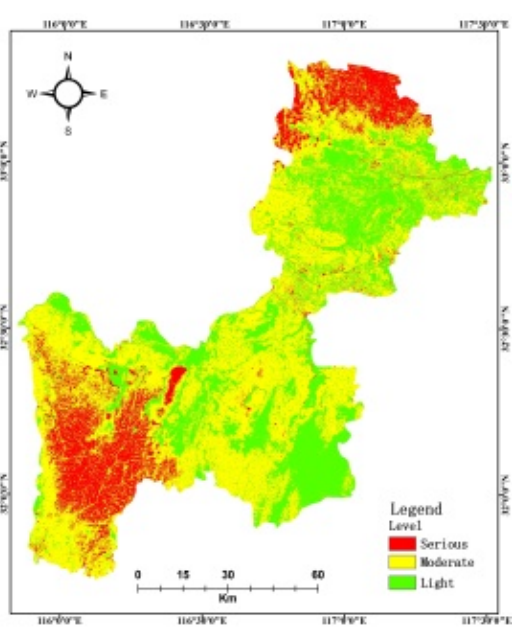

(c)

Figure.2 NDVI images ( $a$ and b) obtained from HJ-A-CCDs images, and (c) the final damage level map rendered three degrees of severity. 
Flood disaster primarily affects growth and yield by defoliating rice, Hence, the rice in different growth stage which suffered by different flood damage degrees can be appeared the spectral character responses obviously. Canopy reflection characteristics of healthy rice illustrate the typical healthy vegetation patterns that have low reflectance in the visible region and high reflectance in the near infrared regions. Comparatively, rice which suffered by seriously flood-damaged shows green diminished and results in higher spectral reflectance in the visible spectrum range, while in the near infrared bands, lower reflectance is observed. Therefore, the analysis of different rice flood-damage levels spectral reflectance indicates that there is a positive correlation between the reflectance and damage levels in the visible band, and which shows as a negative correlation in the NIR band. Similarly, the change trends of Chlorophyll and LAI accordingly decrease with an increase in different damage levels.

In Fig 2 a, on 19 August, after a month to grow, rice in booting to heading stage. Among them, the North of Rice growth is better than South in Huoqiu. Because Dabie Mountain is in the southern of Huoqiu, at the foot of mountain, rice fields could be wash out easily, and the sediment content is high too. Rice growth is good in Shou xian, and north is better than south. Rice growth in Bengbu is worse. In this period, rice suffered from heavy rain and water does not drained in time, and the root system in anaerobic environment for a long time, which can be lead to leaf, contains material outflow, chlorophyll degradation, praline accumulation, and rice growth get more worse. In Fig 2b, on 26 August, the rice in the study area is approaching to mature stage. At this period, rice develop from vegetative growth to reproductive growth. On August 21 to August 22, more than $50 \mathrm{~mm}$ precipitation, leaf and stem of rice in water for a long time in study area, the photosynthesis is abate, rice embryo development was impaired, the grain filling rate was affected, and "flat appear " phenomenon would be appeared which were affect the production seriously. Based on extracted affect rice were suffered by flood damage area, Distribution of rice damage levels was derived (Fig 2 c).

The article choose forty field samples (20 light samples, 10 moderate samples and 10 serious samples) with different degrees to evaluate the identification accuracy of rice flood-induced damage degrees. Confusion matrix was been built to evaluate the accuracy of the rice flood damage degrees result as showed in table2, the result was: (1) overall accuracy was $80 \%$, (2) $\kappa$ value was 0.6907.

$$
K=\frac{N \sum_{i=1}^{r} x_{i i}-\sum_{i=1}^{r} x_{i+} x_{+i}}{N^{2}-\sum_{i=1}^{r} x_{i+} x_{+i}}
$$

$r$ is the total category number; $x_{i i}$ is the correct category number of row $i$, column $i ; x_{i+}$ and $x_{+i}$ are total pixel numbers of row $i$, column $i$; $N$ is the total number of pixels for accurate assessment.

Table 3. Confusion matrix of identification accuracy for different degrees of rice flood damage.

\section{Ground Truth}

\begin{tabular}{llllll} 
& Levels & Serious & Moderate & Light & Total \\
\hline \multirow{3}{*}{ Reference } & Serious & 16 & 1 & 0 & 17 \\
& Moderate & 4 & 8 & 2 & 14 \\
& Light & 0 & 1 & 8 & 9 \\
& Total & 20 & 10 & 10 & 40 \\
\hline
\end{tabular}




\subsection{Growth of rice flood disaster}

The leaf area index (LAI) is a comprehensive index related to the individual characteristics and population characteristics, which, the sum of the area of the single side of the plant leaf above the surface area of the unit ground. LAI is an important factor determining the photosynthesis rate of crops and an important parameter in the process of crop growth.

In this paper, nine common vegetation indices were calculated using HJ-CCD remote-sensing broadband data. The models were constructed nine indices and LAI (an important indicator of longterm growth in rice). In constructing the model form, the article used two model construction methods: (1) Univariate estimation model: Using linear, quadratic and exponential three-way forms and a single vegetation index one by one to build the rice LAI inversion model. The accuracy evaluation and test of the model use the Pearson correlation coefficient and the root mean squared error (RMSE) to evaluate the accuracy of the model. The results were been shown in Table 3. The coefficient of determination for most models is in the range of 0.405-0.701, the RMSE is in the range of 0.681-0.896.

Table4. Constructing LAI inversion based on vegetation index

\begin{tabular}{|c|c|c|c|c|c|c|c|}
\hline \multirow{2}{*}{ Image type } & \multirow{2}{*}{$\begin{array}{l}\text { Vegetation } \\
\text { index }\end{array}$} & \multicolumn{2}{|c|}{ Linear } & \multicolumn{2}{|c|}{ Quadratic } & \multicolumn{2}{|c|}{ Exponential } \\
\hline & & $\mathrm{R}^{2}$ & RMSE & $\mathrm{R}^{2}$ & RMSE & $\mathrm{R}^{2}$ & RMSE \\
\hline \multirow{9}{*}{$\begin{array}{l}\mathrm{HJ}-1 \mathrm{~B} \\
\text { CCD }\end{array}$} & NDVI & $0.561 * *$ & 0.712 & $0.701^{* *}$ & 0.703 & $0.688 * *$ & 0.742 \\
\hline & EVI & $0.405^{* *}$ & 0.828 & $0.525^{* *}$ & 0.740 & $0.540 * *$ & 0.896 \\
\hline & GNDVI & $0.592 * *$ & 0.686 & $0.598 * *$ & 0.681 & $0.706 * *$ & 0.715 \\
\hline & BNDVI & $0.549 * *$ & 0.721 & $0.577 * *$ & 0.699 & $0.651^{* *}$ & 0.773 \\
\hline & GRNDVI & $0.569 * *$ & 0.705 & $0.587^{* *}$ & 0.690 & $0.682^{* *}$ & 0.743 \\
\hline & GBNDVI & $0.569 * *$ & 0.705 & $0.591^{* *}$ & 0.687 & $0.671^{* *}$ & 0.751 \\
\hline & RBNDVI & $0.553^{* *}$ & 0.718 & $0.580^{* *}$ & 0.696 & $0.664^{* *}$ & 0.762 \\
\hline & PNDVI & $0.555^{* *}$ & 0.716 & $0.588^{* *}$ & 0.690 & $0.659^{* *}$ & 0.763 \\
\hline & ANDVI & $0.519 * *$ & 0.745 & $0.580^{* *}$ & 0.696 & $0.615^{* *}$ & 0.802 \\
\hline
\end{tabular}

Based on the above, a single variable and multivariate optimal model were selected to estimate the LAI of rice in the study area. From the formal point of view, the accuracy of the exponential model in the single variable model and the multivariate linear regression model were relatively high. In the actual application and management of crop growth, LAI usually used as a comprehensive reflection of crop growth. Therefore, the paper regards LAI as a measure of whether rice is suffered by flooding or not.

In the models, which build based on nine vegetation indexed, the linear model for inverting LAI constructed by GNDVI has the best accuracy, $\mathrm{R}^{2}$ was 0.592 , and RMSE is 0.686 . Therefore, the LAI inversion model was been constructed using GNDVI as a univariate input variable, and multivariate stepwise regression analysis was used to perform the LAI inversion model. The results shown in Table 5. The model determination coefficient $\mathrm{R}^{2}$ was 0.706 which was used the GNDVI as a single input variable to construct the inversion LAI. In addition, the coefficient of determination $\mathrm{R}^{2}$ was 0.670 for constructing the inversion LAI model with multiple vegetation indices. From the model construction form, the accuracy of the univariate model was higher than that of the multivariate model. This difference may be due to the redundancy of information generated by the multiple spectral feature information in the multivariate model. So, the single variable model used to invert LAI based on GNDVI in the article, the LAI of mapping results in rice planting area are show in Figure 3. In Fig3, on 19 August, in the study area, rice is growing well except for the south and southeast of Huoqiu. In Fig 2b, on 26 August, The overall growth was worse than before August 19, especially in Huoqiu, 
because on August 21 to August 22, there was more than $50 \mathrm{~mm}$ precipitation, which lead to rice in study area suffered by flood damage. However, crop growth is a complex system, and its causative factors are not the only factors that cause disasters. Therefore, after flooding, rice would combined with local habitat factors and its own genetic characteristics to grow. Fig2 showed the spatial distribution map of the key growth period of rice in study area, which can know the disaster distribution in study area. Furthermore, the government can make remedial measures to reduce losses timely.

Table5. LAI inversion model construction

\begin{tabular}{|c|c|c|c|}
\hline Model type & Sensors type & Equation form & $\mathrm{R}^{2}$ \\
\hline Single variable model & $\begin{array}{l}\mathrm{HJ}-1 \mathrm{~B} \\
\mathrm{CCD}^{\mathrm{a}}\end{array}$ & $\mathrm{LAI}=0.794 * \mathrm{e} 2.242 * \mathrm{GNDVI}$ & 0.706 \\
\hline Multi-variable model & $\begin{array}{l}\mathrm{HJ}-1 \mathrm{~B} \\
\mathrm{CCD}^{\mathrm{c}}\end{array}$ & $\begin{array}{c}\mathrm{LAI}=-11.409-27.476 * \mathrm{NDVI}+1.449 * \mathrm{EVI}+28.613 * \mathrm{GNDVI} \\
+29.938 * \mathrm{BNDVI}-18.558 * \mathrm{ANDVI}\end{array}$ & 0.670 \\
\hline
\end{tabular}
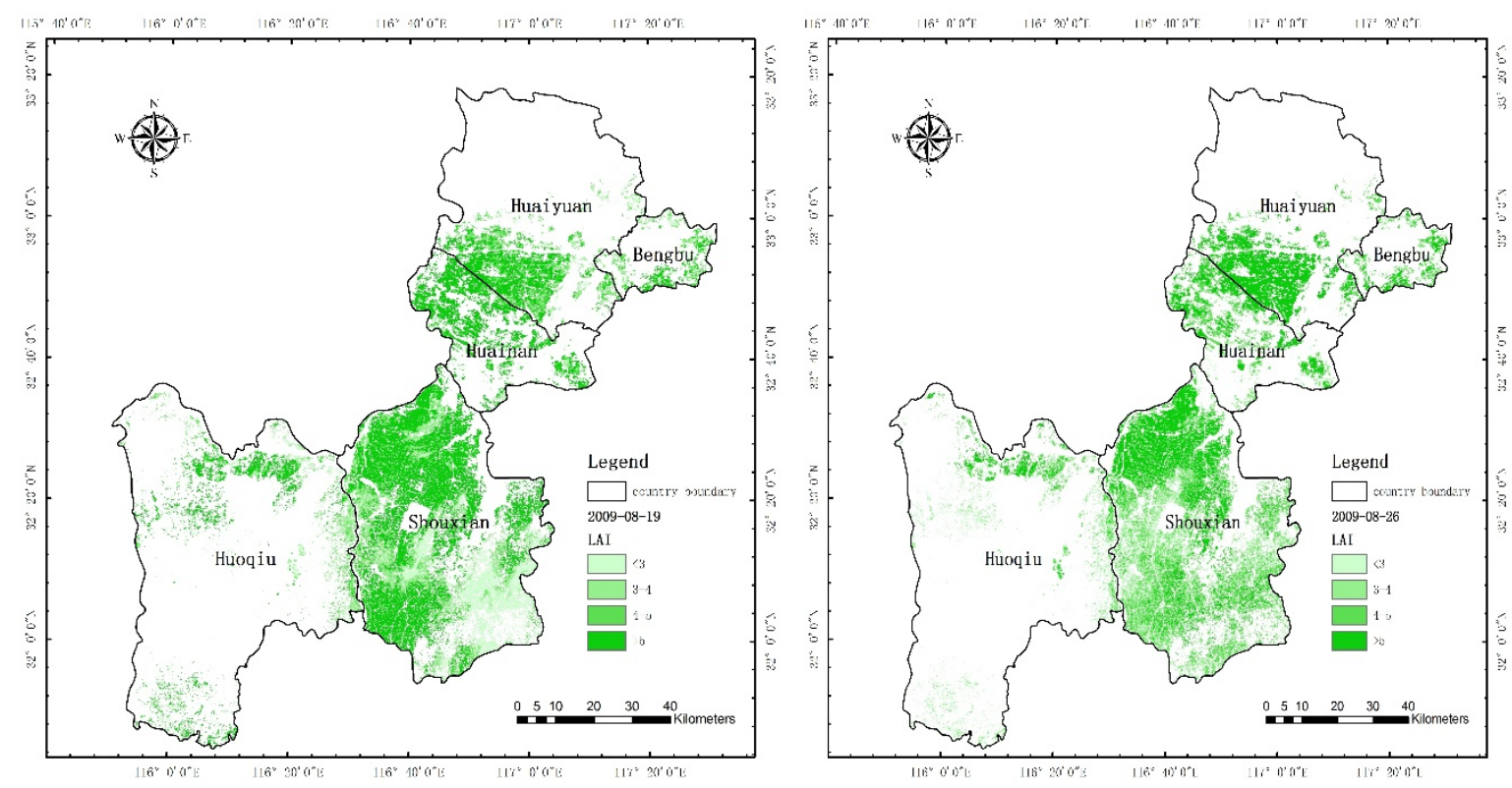

Figure 3. Map of LAI inversion

\section{Conclusion}

This study indicates that domestic remotely sensed images with two days repetition cycle and 30 meters spatial resolution of HJ-1 CCD images can be been applied to detect rice flood damaged relative degrees of rice flood disaster quickly and accurately. The $\Delta$ NDVI image (pre- and post-flood disaster) that calculated from HJ-1 CCD. This method can be effective to identify the degrees of rice flood-damaged, which was sensitive to rice spectral characters change that were suffered by flood disaster. However, due to spatial resolution is low (30 meters), these images are insufficient to derive finer flood damage degrees (serious, moderate and light) from the HJ-1 CCD multi-spectral images, so three relative damage levels were specified according to the thresholds from field investigation data. Furthermore, LAI is a very important indicator that can be reflect the growth of the rice. The article calculated ten VIs from HJ-1 CCD multi-spectral images for find the best VI to invert LAI. According for the accuracy of the model of invert LAI, the article chose the GNDVI to estimate the LAI in study 
area. We can acquire the rice growth that suffered by flood quickly and accuracy.

\section{Acknowledgements}

This research was supported and funded by the National Natural Science Foundation of China (41401415 and 41501481), and Beijing Meteorological Bureau science and technology projects (BMBKJ201704003).

\section{Reference}

1. Mirza MMQ (2003) Climate change and extreme weather events: can developing countries adapt Climate Policy 3: 233-248

2. Tai FJ, Yuan ZL, Wu XL, Zhao PF, Hu XL, Wang W (2011) Identification of membrane proteins in maize leaves, altered in expression under drought stress through polyethylene glycol treatment. Plant Omics 4(5):250-256

3. Li Cuijin. Statistical Analysis of China’s Heavy Rain Flood [M]. Science of Disaster, 1996:59-63

4. Mateeul Hap, Memon Akhtar, Sher Muhammad, et al. Techniques of remote sensing and GIS for flood monitoring and damage assessment: A case study of Sindh province, Pakistan [J]. The Egyptian Journal of remote sensing and space science, 2012, 15: 135-141

5. Liang Yitong, Liu Kequn, Zhou Shouhua, et al. The Technical Method of Monitoring of Flood Disaster Due to Torrential Rain using EOS-MODIS [J]. Torrential Rain and Disaster, 2008, 27(1): 64-66.

6. Goro Mouri, Daigo Minoshima, Valentin Golosov, et al. Probability assessment of flood and sediment disasters in Japan using the Total Runoff-integrating Pathways model [J]. International Journal of Disaster Risk Reduction, 2013, 3 (1):31-43.

7. Subash N, Mohan H S R, Sikka A K. Quantitative assessment of influence of monsoon rainfall variability on rice production over India [J]. Journal of Agro Meteorology,2009,11(2): 109-116

8. Wang Fumin, Derivating rice parameters from hyperctral reflectance and its system development, and rice cultivated areas extraction using remote sensing, Zhejiang University, [D], 2007

9. Liu Zhanyu, Huang Jingfeng, Wang Fumin, Wang Yuan. Adjusted-Normalized Difference Vegetation Index for Estimating Leaf Area Index of Rice. Science Agriculture sinica. [J], 2008, 41(10):3350-3356.

10. Rouse J W, Hass R H, Schell J A, et al., Monitoring the vernal advancement of retrogradation of natural vegetation[R]. NASA/GSFC, Type III, Final Report. Greenbelt, MD, 1974: 371.

11. Gitelson A. A., Merzlyak, M. N., Chivkunova, O. B. Optical properties and nondestructive estimation of anthocyanin content in plant leaves. Journal of Photochemistry and Photobiology, 2001, 74(1): 38-45.

12. Huete Alfredo, Chris Justice. MODIS vegetation index (MOD 13) Algorithm theoretical basis documents, Vision 3. 1999. 